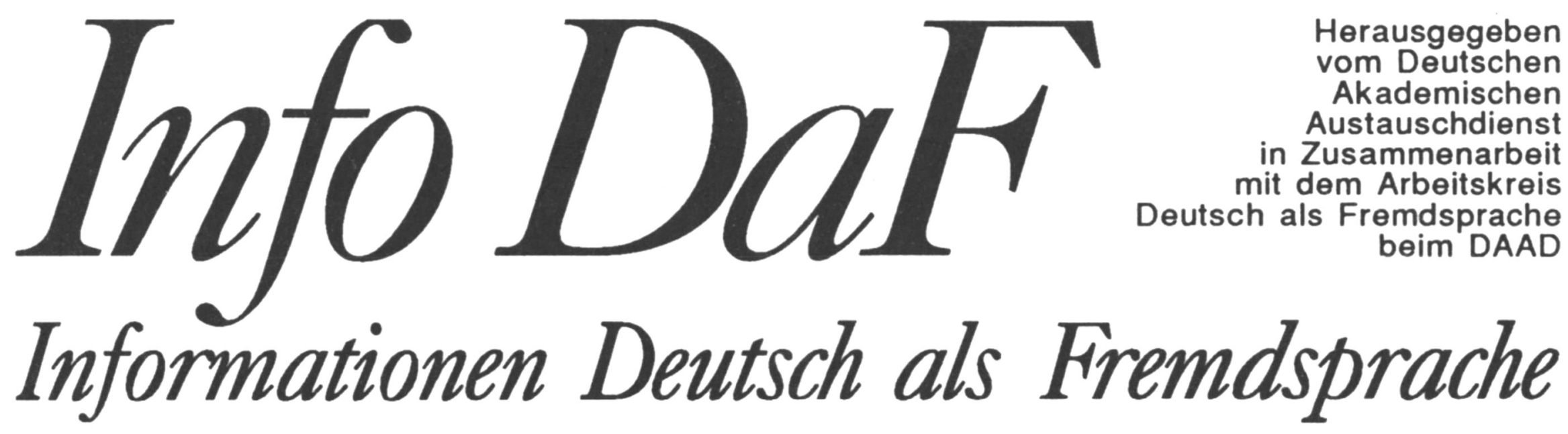

Nr. 2

17. Jahrgang

DAD

Mai 1990

\title{
Inhalt
}

Artikel

Norbert Dittmar, Astrid Reich, Magdalene Schumacher, Romuald Skiba, Heiner Terborg (Projekt P-MoLL)

Die Erlernung modaler Konzepte des Deutschen durch erwachsene polnische Migranten. Eine empirische Längsschnittstudie

Monika Lindhorst

KLYCCHEES: Unerkannte Fremdheitsfantasien - am Beispiel sIndien

DaF im Ausland

Andreas F. Kelletat und Holger Siegel

Aspekte transkulturellen kommunikativen Handelns. Zur Dichotomie von Fremdem und Eigenem im tripolaren Ansatz

Didaktik Deutsch als Fremdsprache / Aus der Praxis

\section{Uwe Koreik}

Interaktive Institutionenkunde, Ein Unterrichtsvorschlag zum Thema "Wahlsystem « - Wahlrecht spielerisch im Vergleich

Klaus Munsberg

Die WDR-Sendereihe ZeitZeichen. Einsatzmöglichkeiten im DaF-Unterricht

\section{Rezensionen}

Sperber, Horst G.: Mnemotechniken im Fremdsprachenerwerb mit Schwerpunkt Deutsch als Fremdsprache (Roland Meinert und Carl-Jochen Dill)

Steinig, Wolfgang: Schüler machen Fremdsprachenunterricht (Roland Meinert und Carl-Jochen Dill) 
Tagungsankündigungen
Einladung zur Fachtagung "Phonetik, Ausspracheschulung, Sprecherziehung im Bereich Deutsch als Fremdsprache" am 19.-22. September 1990 in Regensburg

Fachverband Deutsch als Fremdsprache (FaDaF)

Über die Autoren

Abstracts 